\title{
Carcinoma quístico unilocular
}

\author{
Gómez-Ferrer Lozano A, Navarro Antón JA, Sala Aznar A, Mola Arizo Mํㅣ, Polo i Peris AC.
}

Servicio de Urología, Hospital Lluís Alcanyís de Xàtiva, Valencia.

Actas Urol Esp. 2007; 31(7):792-795

\section{RESUMEN}

\section{CARCINOMA QUÍSTICO UNILOCULAR}

Presentamos el caso de un carcinoma quístico unilocular de riñón y sus imágenes radiológicas. Los carcinomas quísticos de riñón representan un escaso porcentaje de las tumoraciones malignas renales (3-7\%). La presencia de masas quísticas en el riñón puede plantear dificultad en su diagnóstico diferencial, como ocurrió en nuestro caso, especialmente las uniloculares.

Palabras clave: Carcinoma renal. Unilocular. Diagnóstico diferencial. Quiste renal.

\section{ABSTRACT}

\section{UNILOCULAR CYSTIC RENAL CARCINOMA}

We report the case of unilocular cystic renal cell carcinoma and its radiological findings. Cystic renal cell carcinomas are among 3 to $7 \%$ of kidney cancers and sometimes are difficult to diagnose, as it happened in this case.

Keywords: Cystic renal cell carcinoma. Unilocular. Cystic kidney diagnosis.

$\mathrm{L}$ os carcinomas renales pueden presentar una apariencia quística uni o multilocular hasta en el $15 \%$ de los casos. En muchas ocasiones la filiación de las masas quísticas renales puede ser muy dificil de establecer y es frecuente la necesidad de su exéresis para el diagnóstico exacto. Esto es especialmente cierto en el caso de las tumoraciones quísticas uniloculares y homogéneas radiológicamente, como es el caso que describimos a continuación.

Presentamos el caso de un paciente varón de 46 años que consulta por sensación de masa en hemiabdomen izquierdo asintomática. A la exploración se constata la presencia de una masa indolora, de consistencia elástica, de superficie lisa y a tensión. Se practica ecografia abdominal que informa de tumoración redondeada de contenido anecoico dependiente del polo inferior del riñón izquierdo. Se realiza punción-aspiración con el diagnóstico de quiste renal cortical gigante, obteniendo muestra para citología con resultado negativo y procediendo a la esclerosis de sus paredes (Fig. 1).
Un mes después el paciente acude a consulta refiriendo síndrome constitucional con astenia, anorexia, febrícula y dolor sordo en flanco izquierdo. Se realiza hemograma que revela anemia normocrómica normocítica y nueva ecografía con persistencia de la formación quística. Se solicita TAC que demuestra la existencia de una masa redondeada de contenido líquido homogéneo y paredes engrosadas dependiente del polo inferior del riñón izquierdo (Fig. 2). Se realiza nueva punción y drenaje pensando que se trata de un quiste infectado, pero tras evacuación del contenido y nuevo intento de esclerosis se objetiva dos semanas más tarde la persistencia de la tumoración.

Se programa entonces tratamiento quirúrgico procediendo a quistectomía por lumbotomía. En el acto quirúrgico se evidencia una pared engrosada con abundante material necrótico y fibrinoide en la cara interna de la pared quística, solicitando biopsias peroperatorias con resultado negativo para neoplasia. 


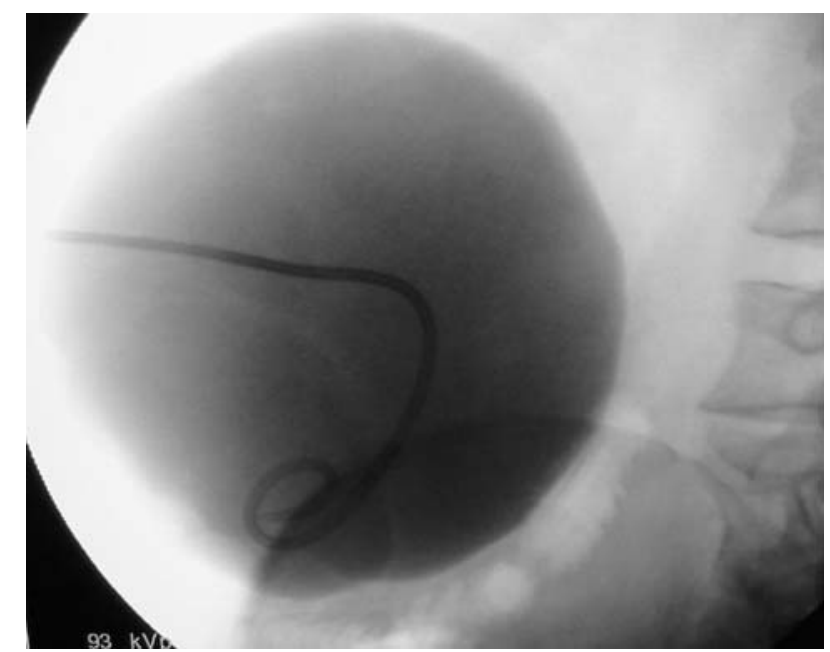

FIGURA 1. Quistografía por punción.

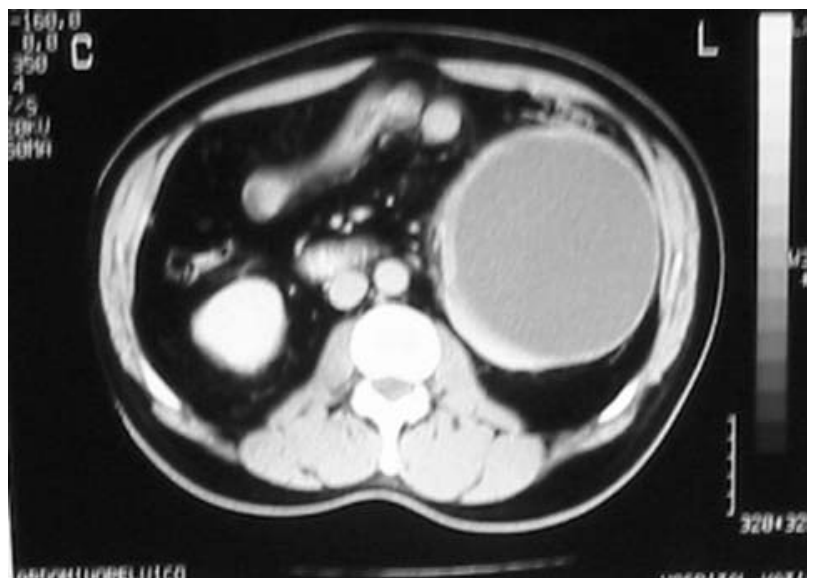

FIGURA 2. TAC: Imagen quística homogénea de gran tamaño en polo inferior de riñón izquierdo.

Se consigue la exéresis de todo el quiste a excepción de un mínimo casquete en polo inferior del riñón.

El informe histológico de la pieza revela la presencia de carcinoma de células renales en el espesor de la pared quística en toda la extensión conformando una cápsula completa de tejido neoplásico (Fig. 3 y 4). Ante la duda de haber dejado tejido neoplásico en el casquete polar se decide completar la nefrectomía que se realiza por el mismo abordaje 3 meses después. El estudio del riñón demuestra la persistencia de escasa cantidad del mencionado tejido neoplásico en el polo inferior del riñón. El paciente evoluciona satisfactoriamente y está asintomático al año de completar la nefrectomía.

\section{DISCUSIÓN}

La apariencia quística de las neoplasias renales está descrita entre el 1 al 15\% de los tumores renales. Este porcentaje tan variable depende de autores y de los criterios utilizados para definir al tumor como quístico o no. Hartman ${ }^{1}$ describe cuatro posibles mecanismos en el desarrollo de las tumoraciones quísticas: necrosis quística central del tumor, malignización en la pared de un quiste simple previo, crecimiento multilocular de un verdadero tumor y tumor unilocular. Solo en estos dos últimos casos se debe considerar a la neoplasia como verdaderamente quística y se ha establecido que el componente histológico no debe superar el $25 \%$ de la masa para considerarlo como tal. $\mathrm{El}$ restante $75 \%$ debe corresponder a auténtico contenido líquido y sin componente de necrosis.

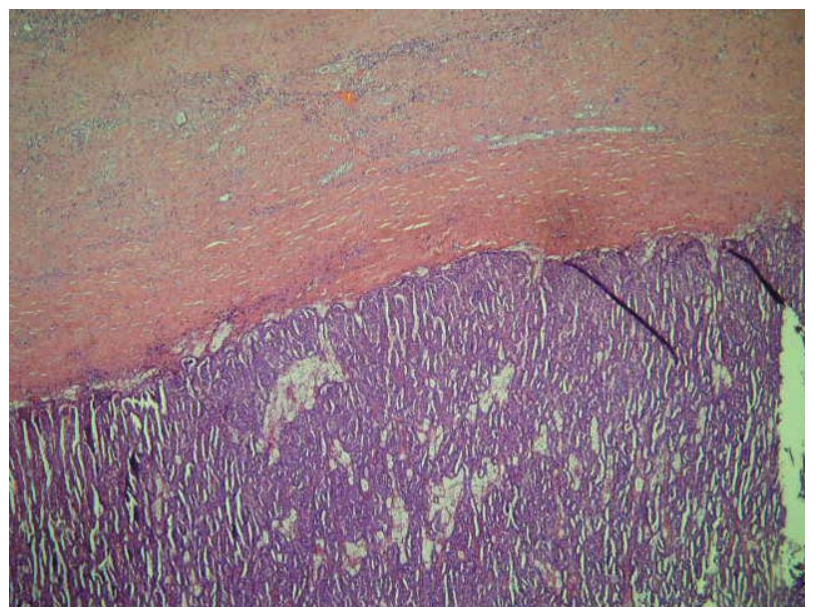

FIGURA 3. A.P. Pared fibrosa de la tumoración quistica revestida por tejido neoplásico.

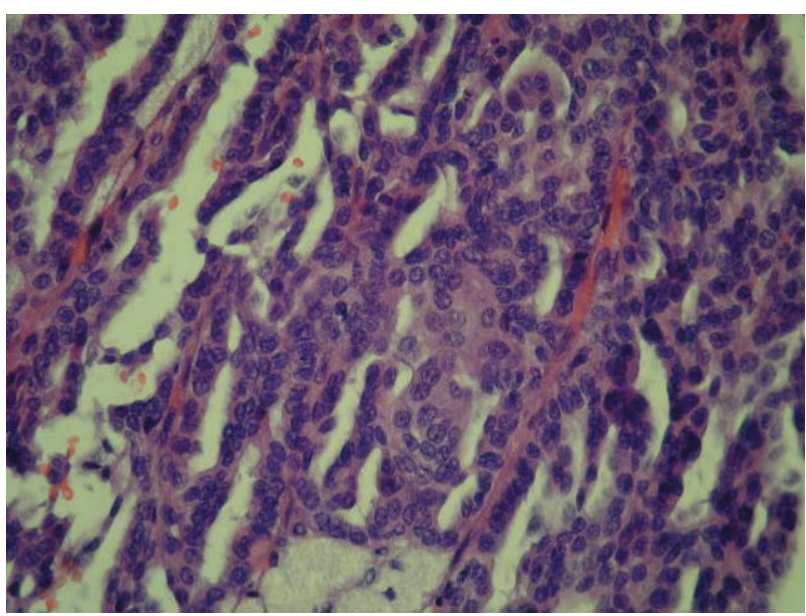

FIGURA 4. A.P. Detalle del carcinoma de túbulos renales. 
La mayoría de los tumores quísticos corresponden a carcinomas multiloculares y se han comunicado muchísimos menos casos de carcinomas quísticos uniloculares, situándose entre el $10^{2}, 20^{3}$ y el $30 \%$ de los casos $^{4}$.

Este tipo de tumores pueden ocasionar importantes dificultades diagnósticas preoperatorias. Varias características radiológicas deben hacer sospechar la posibilidad del diagnóstico de carcinoma quístico entre las que cabe mencionar: paredes engrosadas y/o irregulares, contenido no completamente anecoico, densidades radiológicas altas, presencia de neovascularización, etc, aunque la ausencia de la misma no excluya este diagnóstico.

Bosniak realizó una clasificación de los quistes renales en cuatro tipos en función de sus características radiológicas, originalmente en imágenes de TAC., aunque dicha clasificación también se aplica en estudios de ecografía y RNM. Una revisión reciente ${ }^{5}$ describe cinco categorías y orienta la actitud a seguir en cada caso (Tabla 1). El caso concreto de nuestro paciente corresponde a un quiste Bosniak tipo III.

Tabal 1. Clasificación de quistes renales de Bosniak

I Quiste benigno simple de pared fina sin tabicaciones, calcificaciones ni componentes sólidos. Densidad radiológica agua sin realce radiológico con contraste.

II Quiste benigno con tabiques de pared fina y leve realce. Pequeña calcificación o segmento corto de pared engrosado o calcificado. Lesiones uniformes de alta atenuación menores de $3 \mathrm{~cm}$ (llamados quistes de alta densidad) bien diferenciadas sin realce. Los quistes de esta categoría no precisan de seguimiento.

II F (F de follow-up, seguimiento) Quistes multitabicados y/o con tabiques o pared gruesa. Calcificaciones gruesas o nodulares. Sin realce significativo a la administración de contraste. Lesiones totalmente intrarrenales de más de $3 \mathrm{~cm}$. Se recomienda seguimiento.

III Quistes “complicados” de pared gruesa, irregular, tabicadas o no con realce medible a la infusión de contraste. Lesiones a explorar quirúrgicamente, que pueden corresponder a patología benigna o maligna (carcinoma renal quístico uni o multilocular).

IV Lesiones claramente malignas que cumplen los criterios III pero que además presentan tejido con realce adyacente pero independiente de la pared del quiste. Incluyen carcinomas quísticos y precisan de exéresis quirúrgica.
En general, la ecografia y la TAC. nos conducirán a un diagnóstico de sospecha y hay que hacer el diagnóstico diferencial con otros procesos, generalmente infecciosos, inflamatorios o traumáticos, que pueden presentarse con imágenes parecidas según se trate de un masa uni o multilocular (Tabla 2 y 3 ).

Tabla 2. Masa quística unilocular

(que no cumple todos los criterios diagnósticos de quiste simple

Carcinoma quístico

Quiste hemorrágico

Quiste infectado

Absceso

Pielonefritis xantogranulomatosa focal

Malacoplaquia

Quiste hidatídico

Hematoma organizado

Aneurisma o malformación vascular

Tabla 3. Masa quística multilocular

Carcinoma quístico multilocular (origen tubular)

Nefroma quístico multilocular (origen blastomérico)

Quiste multitabicado

Displasia multiquística segmentaria

Quiste infectado

Pielonefritis xantogranulomatosa focal

Malacoplaquia

Quiste hidatídico

Hematoma organizado

Aneurisma o malformación vascular.

La realización de punción-aspiración puede ser de ayuda si conduce a un diagnóstico de malignidad $^{1}$ y hay que sospecharlo si el contenido es hemorrágico, pero la presencia de un líquido claro con citologías negativas tampoco representa necesariamente la benignidad del quiste, como ocurrió en nuestro caso. Pensamos, después de nuestra experiencia, que la imposibilidad de esclerosis de las paredes del quiste en dos ocasiones tal y como nos sucedió debe de hacer sospechar la posibilidad de malignidad, aunque este dato no lo hemos observado en ninguno de los artículos de nuestra bibliografia. 
La mayoría de los autores ${ }^{2,4}$ que han estudiado la evolución de estos tumores observan un comportamiento más benigno en estas variantes histológicas que en las neoplasias sólidas y prácticamente en todos los casos estudiados la exéresis del tumor, bien mediante nefrectomía total o parcial ha conducido a la completa curación de los pacientes, pero es preciso diferenciar entre el tumor verdaderamente quístico y la neoplasia con necrosis central, pues esta última conlleva un peor pronóstico.

\section{CONCLUSIONES}

El diagnóstico de carcinoma quístico puede llegar a ser difícil y hay que sospecharlo ante la presencia de masas quísticas uni o mulitiloculares de paredes engrosadas, irregulares y/o con contenido heterogéneo. La práctica de una punción-aspiración puede no ser concluyente y no basta para descartar este proceso. La extirpación completa del tumor suele conducir a la resolución definitiva del problema.

\section{REFERENCIAS}

1. Hartman DS, Davis CJ, Johns T, Goldman SM Cystic renal cell carcinoma. Urology.1986; 28 (2):145- 153.

2. Koga S, Nishikido M, Hayashi T, Matsuya F, Saito Y, Kanetake Outcome of surgery in cystic renal cell carcinoma. H. Urology 2000; 56(1):67-70.

3. Yamashita Y, Watanabe O, Miyakazi T, Yamamoto H, Harada M, Takahashi M Cystic renal cell carcinoma. Imaging findings with pathologic correlation. Acta Radiológica 1994; 35(1):19-24.

4. Han K, Janzen NK, McWhorter VC, Kim HL, Pantuck AJ, Zisman A, Figlin RA et al Cystic renal cell carcinoma: biology and clinical behavior. Urol Oncol. 2004; 22(5):410-414.

5. Israel GM, Bosniak MA An update of the Bosniak renal cyst classification system. Urology. 2005;66:484-488.

Correspondencia autor: Dr. A. Gómez-Ferrer Lozano Servicio de Urologia. Hospital Lluis Alcanyis.

Ctra. Xátiva-Silla, Km. 2 - 46800 Xátiva (Valencia)

Tel.: 962289500

E-mail autor: gomez_alvloz@gva.es

Información artículo: Nota Clínica

Trabajo recibido: marzo 2006

Trabajo aceptado: mayo 2006 